\title{
Effects of the Ethanolic Extracts of Guava Leaves, Licorice Roots and Cloves on the Cariogenic Properties of Streptococcus mutans
}

\author{
Nalita Phaiboon, Pawitra Pulbutr, Bunleu Sungthong, Sakulrat Rattanakiat*
}

Nalita Phaiboon, Pawitra

Pulbutr, Bunleu Sungthong, Sakulrat Rattanakiat*

Pharmaceutical Chemistry and Natural Product Research Unit (PCNRU), Faculty of Pharmacy, Mahasarakham University, Kantharawichai, Maha Sarakham 44150, THAILAND.

\section{Correspondence}

\section{Sakulrat Rattanakiat}

Ph.D. Asst. Prof. Pharmaceutical

Chemistry and Natural Product Research

Unit (PCNRU), Faculty of Pharmacy,

Mahasarakham University, Kantharawichai,

Maha Sarakham 44150, THAILAND.

E-mail: sakulrat.r@msu.ac.th

History

- Submission Date: 28-06-2019;

- Review completed: 10-07-2019;

- Accepted Date: 22-07-2019.

DOI : 10.5530/pj.2019.11.162

Article Available online

http://www.phcogj.com/v11/i5

\section{Copyright}

(C) 2019 Phcogi.Com. This is an openaccess article distributed under the terms of the Creative Commons Attribution 4.0 International license.

\begin{abstract}
Introduction: Streptococcus mutans is a major causative pathogen of dental caries. This study aimed to investigate the effects of the ethanolic extracts of Psidium guajava, Glycyrrhiza glabra and Syzygium aromaticum against cariogenic properties of Streptococcus mutans. These medicinal plants have been used traditionally as the ingredients in the herbal mouthwash for the management of dental caries. Methods: The 95\% ethanolic extracts of these medicinal plants were prepared and their phytochemical contents were analyzed by using thin layer chromatography-densitometry. Antibacterial activities of the extracts against $S$. mutans were evaluated according to broth dilution method. The effects of the extracts against cariogenic properties of $S$. mutans, which are surface adherence, biofilm formation and acid production, were also investigated. Results: The biological active constituents, quercetin, glycyrrhizic acid and eugenol, were found in P. guajava, G. glabra and S. aromaticum, respectively. The three extracts possessed anti-bacterial activity against $S$. mutans with the MICs of $1.562,0.195$ and $1.562 \mathrm{mg} / \mathrm{mL}$, respectively. The extracts at every concentration tested (at lower than their MICs) significantly inhibited cariogenic properties of S. mutans, which included inhibitions against surface adherence, biofilm formation and acid production. Conclusions: The ethanolic extracts of guava leaves, licorice roots and cloves produced anti-bacterial and anti-cariogenic activities against $S$. mutans. These plant extracts thus can potentially be developed as a product for the prevention of dental caries in the near future.
\end{abstract}

Key words: Cariogenic properties, Streptococcus mutans, Psidium guajava, Glycyrrhiza glabra, Syzygium aromaticum

\section{INTRODUCTION}

Dental caries (tooth decay) is an important oral infection, which is commonly found in people at any age. In Thailand, the incidence of dental caries was reported at $66-90 \%$ in $2007 . .^{1}$ Although many types of bacteria are found to be involved in the etiology of dental caries, Streptococcus mutans, gram-positive acid-producing cocci, is a major causative agent of dental caries in humans. ${ }^{2}$ The virulence of $S$. mutans involves its crucial cariogenic properties, including biofilm formation, surface adherence and acid production. The formation of bacterial biofilm or dental plaque on the tooth surface plays an important role in the pathogenesis of dental caries. The biofilm-forming bacteria can metabolize fermentable carbohydrates, especially sucrose into acid, which aggressively dissolve the mineral components of tooth structure. These lead to tooth demineralization, which subsequently results in dental caries. Dental caries can be treated by using several dental procedures, including tooth filling, root canal treatment and antibacterial therapy. Nonetheless, these methods need to be performed exclusively by the dentist. The preventions of dental caries by tooth brushing and using mouthwash and dental floss, are thus the better strategy to tackle dental caries. Some chemicals such as chlorhexidine and triclosan, are used in oral health-care products to eradicate acid-producing bacteria and prevent dental caries.
However, there are some limitations of these agents such as tooth discoloration, oral and gastrointestinal irritations, and taste disturbance. The overuse of these substances may also destroy the normal flora and give rise to superinfection and antibacterial resistance. $^{3}$ Therefore, using herbal products with anti-cariogenic activity is an interesting alternative for the prevention of dental caries.

Several medicinal plants, specifically guava (Psidium guajava L.), licorice (Glycyrrhiza glabra L.) and clove (Syzygium aromaticum L.), have been traditionally used in herbal mouthwash formula for the management of dental caries in Thai folk medicine $^{4}$ Leaves of guava, which belongs to the Myrtaceae family has been adopted in folklore practices to maintain the oral hygiene. ${ }^{5}$ Licorice is a perennial herb in the Fabaceae family, which its roots has been consumed widely for the treatment of upper respiratory ailments including coughs, sore throat and bronchitis. ${ }^{6}$ Cloves (buds of $S$. aromaticum, which belong to the Myrtaceae family) have been applied traditionally for dental health care because of its antibacterial, anti-inflammatory, and analgesic effects. ${ }^{7}$ It was reported that the ethanolic extracts of these three medicinal plants possessed the antibacterial activity against $S$. mutans. ${ }^{4}$ However, the anti-cariogenic properties of these extracts have not been clearly established. This study thus aimed to investigate the antibacterial and anti-cariogenic properties, i.e. inhibitions of biofilm formation,

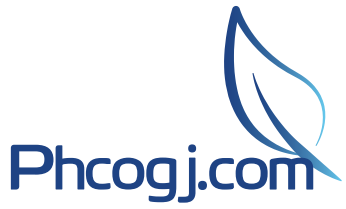

Cite this article: Phaiboon N, Pulbutr P, Sungthong B, Rattanakiat S Effects of the Ethanolic Extracts of Guava Leaves, Licorice Roots and Cloves on the Cariogenic Properties of Streptococcus mutans. Pharmacog J. 2019;11(5):1029-36. 
surface adherence and acid production, of the ethanolic extracts of guava leaves, licorice roots and cloves. Additionally, the phytochemical constituents of the extracts were also analyzed by using thin-layer chromatography-densitometry. The results obtained from this study would provide essential information for the formulation of herbal oral health-care products with anti-caries activity, which potentially enhance the value of local medicinal plants in the country.

\section{MATERIALS AND METHODS}

\section{Materials}

Ethanol (RCI Labscan, Thailand), Dimethyl sulfoxide; DMSO (Carlo Erba reagent, France), Brain Heart Infusion; BHI (Becton Dickinson and company, France), Sodium hydroxide; $\mathrm{NaOH}$ (Carlo Erba reagent, France), Chlorhexidine (Maharat Nakhon Ratchasima Hospital, Thailand), Potassium chloride; $\mathrm{KCl}$ (Carlo Erba reagent, France), Magnesium chloride; $\mathrm{MgCl}_{2}$ (RCI Labscan, Thailand), Formalin (Carlo Erba reagent, France), Sodium acetate (RCI Labscan, Thailand), Crystal violet (Loba Chemie, India), Potassium hydroxide; $\mathrm{KOH}$ (Carlo Erba reagent, France), Sucrose (RCI Labscan, Thailand)

\section{Plant materials and preparations of the herbal extracts}

Fresh leaves of guava (Psidium guajava L.) were collected from Nakhon Ratchasima province, Thailand, whereas dry rhizomes of Glycyrrhiza glabra L. and dry buds of Syzygium aromaticum L. were purchased from the herb shops in Nakhon Ratchasima province and Mahasarakham province, Thailand, respectively. These herbs were authenticated by Asst. Prof. Dr. Wanida Caichompoo a botanist at Faculty of Pharmacy, Mahasarakham University, Thailand. The plant materials were separately extracted. The sample was dried at $50^{\circ} \mathrm{C}$ for 24 hours in a hot air oven. All dried herbs were ground to powders. To obtain the crude extracts, pulverized herbs were macerated in 95\% ethanol (1:10 $\mathrm{w} / \mathrm{v}$ ) for 7 days. The macerates were filtered and dried by using a rotary evaporator. The crude extracts were stored at $-20^{\circ} \mathrm{C}$ until further use.

\section{Bacterial strain and growth condition}

Streptococcus mutans DMST 18777; S. mutans used in this study was obtained from the Department of Medical Sciences, Ministry of Public Health, Thailand. The culture was grown in brain heart infusion (BHI) broth at $37^{\circ} \mathrm{C}$ in the presence of $5 \% \mathrm{CO}_{2}$ and the optical density (OD) value of $S$. mutans was $0.08-0.10$ with UV spectrophotometer at the wavelength of $600 \mathrm{~nm}$.

\section{Thin layer chromatography-densitometric method}

The plant extracts $(50 \mathrm{mg} / \mathrm{mL})$ and the phytochemical standards (quercetin, glycyrhizic acid and eugenol) $(0.1 \mathrm{mg} / \mathrm{mL})$ were spotted on a sheet of aluminum coated silica gel 60 types $\mathrm{F}_{254}$ (TLC plate). The TLC plate was dipped in a glass container containing the mobile phase (toluene: ethyl acetate: methanol: formic acid in a ratio of 3: 4: 1: 1 (\% $\mathrm{v} / \mathrm{v})) .{ }^{8}$ The TLC plate was removed and left dry at the room temperature. The chromatogram was detected with a densitometer under the UV at the wavelength of $254 \mathrm{~nm}$.

\section{Determinations of minimum inhibitory concentration (MIC) and minimum bactericidal concentration (MBC)}

The minimum inhibitory concentration (MIC) was determined by using a broth dilution method. The extract dilutions were made in several two-fold decreasing concentrations with BHI broth containing $10 \%$ dimethyl sulfoxide (DMSO) from $0.024 \mathrm{mg} / \mathrm{mL}$ to $12.5 \mathrm{mg} / \mathrm{mL}$. One milliliter of standard inoculum was seeded into 1-ml dilution. All test tubes were incubated at $37^{\circ} \mathrm{C}$ in the presence of $5 \% \mathrm{CO}_{2}$ for 24 hours. After the incubation, the turbidity was observed to indicate the bacterial growth. MIC was determined as the highest dilution (that is, the lowest concentration) of the extract that showed no visible growth Two control tubes, positive and negative controls, were also performed. Chlorhexidine was used as the positive control whereas 10\% DMSO (vehicle) was used as the negative control., ${ }^{9110}$

The minimum bactericidal concentration (MBC) was determined by using a drop plate method. The test tubes with no bacterial growth in the broth dilution method were subsequently used for the $\mathrm{MBC}$ determination. $100 \mu \mathrm{L}$ of culture was subcultured onto $\mathrm{BHI}$ agar and incubated for further 24 hours at $37^{\circ} \mathrm{C}$ in the presence of $5 \% \mathrm{CO}_{2}$. The least concentration, at which no growth was observed, was noted as the MBC..$^{910}$

\section{Sucrose-dependent and sucrose-independent adherence assays}

The adherence assay of $S$. mutans on smooth glass surface was conducted according to the method of Prabu, Gnanamani \& Sadulla (2006) with some modifications. The extracts at the sub-MICs or vehicle were added into the glass tubes containing S. mutans $\left(1.5 \times 10^{8} \mathrm{CFU} / \mathrm{mL}\right)$ in BHI broth $(10 \mathrm{~mL})$. For the sucrose-dependent adherence assay, sucrose $(5 \% \mathrm{w} / \mathrm{v})$ was included in the incubation media. Contrarily, sucrose was omitted in the incubation media of the sucrose-independent assay. The glass tubes, tilted at an angle of 30 degree, were incubated at $37^{\circ} \mathrm{C}$ in $5 \% \mathrm{CO}_{2}$ incubator for 24 hours. The optical density of the decanted media was determined at the wavelength of $600 \mathrm{~nm}$ after the 24-hour incubation, in order to obtain the amount of non-adhered cells of $S$. mutans. The cells of $S$. mutans adhered on the glass surface were removed by adding $2 \mathrm{~mL}$ of $0.5 \mathrm{M} \mathrm{NaOH}$. The amount of adhered cells of $S$. mutans was indicated by the optical density at the wavelength of $600 \mathrm{~nm}$ of the $\mathrm{NaOH}$-washed up mixture. The optical density of the total cells of $S$. mutans was calculated by the sum of the optical density of the non-adhered cells and the adhered cells. \% adherence was calculated as follows

$\%$ adherence $=\left(\left(\mathrm{OD}_{600}\right.\right.$ of adhered cells $\left.) \times 100\right) /\left(\mathrm{OD}_{600}\right.$ of total cells $)$

\section{Biofilm formation assay}

The biofilm formation assay was performed following the method of Bowen \& Koo (2011) with slight modifications. The BHI broth $(5 \mu \mathrm{L})$ containing sucrose $(5 \% \mathrm{w} / \mathrm{v})$ was used as an incubation media for $S$. mutans $\left(1.5 \times 10^{8} \mathrm{CFU} / \mathrm{mL}\right)$. The extracts at the sub-MICs or vehicle were added into the incubation media and incubated at $37^{\circ} \mathrm{C}$ for 6,12 , 20 or 24 hours. At the designated time points, the planktonic cells of $S$. mutans were removed from the microplate well by decanting the media. The remaining unattached cells were washed gently with sterile deionized water. Formalin (37\%, diluted $1: 10)$ and $2 \%$ sodium acetate were added into the microplate well to fix the biofilm formed by $S$. mutans. $0.1 \%$ crystal violet $(200 \mu \mathrm{L})$ was subsequently added and left for 15 minutes to stain the biofilm. The stained biofilm was rinsed twice with sterile deionized water. $150 \mu \mathrm{L}$ of $95 \%$ ethanol was then added in order to remove the crystal violet dye from the biofilm. After 10-minute shaking, the volume of $100 \mu \mathrm{L}$ was pipetted out and the optical density of the mixture was measured at the wavelength of $600 \mathrm{~nm}$. \% inhibition of biofilm formation was calculated from the following equation:

$$
\begin{aligned}
& \% \text { inhibition of biofilm formation }=\left(\left(\mathrm{OD}_{600} \text { vehicle }-\mathrm{OD}_{600} \text { extract }\right)\right. \\
& \times 100) /\left(\mathrm{OD}_{600} \text { vehicle }\right)
\end{aligned}
$$

\section{Glycolytic pH drop assay}

The glycolytic $\mathrm{pH}$ drop assay was carried out according to the method of Yang et al. (2016). The suspensions of $S$. mutans at the concentration of $7.5 \times 10^{8} \mathrm{CFU} / \mathrm{mL}$ were prepared and washed with a solution of $\mathrm{KCl}(50$ $\mathrm{mM})$ and $\mathrm{MgCl}_{2}(1 \mathrm{mM})$. The bacterial suspension was mixed with the extracts at their sub-MICs or vehicle. The $\mathrm{pH}$ of $S$. mutans suspension was adjusted to 7.2-7.4 by using $\mathrm{KOH}(0.2 \mathrm{M})$. At the beginning of the 
$\mathrm{pH}$ record, a glucose solution at the final concentration of $0.5 \% \mathrm{w} / \mathrm{v}$ was added into the $S$. mutans suspension. The $\mathrm{pH}$ of the $S$. mutans suspension was constantly monitored for 60 minutes. The changes of $\mathrm{pH}$ during the first 10 minutes $(0-10$ minutes $)$ was indicated as the initial rate of $\mathrm{pH}$ drop.

\section{Statistical analysis}

The phytochemical contents of the extracts were shown as mean $\pm \mathrm{SD}$ whereas the anti-cariogenic activities were reported as mean \pm SEM (\% adherence and $\%$ inhibition of biofilm formation) or mean \pm SD (initial rate of $\mathrm{pH}$ drop). The statistical analysis was conducted by one-way analysis of variance (ANOVA) followed by Bonferroni post-hoc test. The data were considered as significant difference when $p$-value is less than 0.05 .

\section{RESULTS}

\section{Phytochemical analysis by using TLC-densitometry}

The results of phytochemical analysis of the ethanolic extracts of guava leaves, licorice roots and cloves by using TLC-densitometry are shown in Table 1 . The Rf values detected at the UV wavelength of 254 $\mathrm{nm}$ of the ethanolic extracts of guava leaves, licorice roots and cloves were approximate to those of quercetin, glycyrrhizic acid and eugenol, respectively. The amounts of the phytochemical detected in the extracts from the densitogram analysis are also shown in Table 1.

\section{The anti-bacterial activity of the extracts against $\mathrm{S}$.} mutans

The ethanolic extracts of guava leaves, licorice roots and cloves inhibited the growth of S. mutans with the MICs shown in Table 2. The ethanolic extract of licorice roots also had bactericidal activity with the MBC of $3.12 \mathrm{mg} / \mathrm{mL}$. However, the bactericidal activity was not found with the ethanolic extracts of guava leaves and cloves at the highest concentrations tested $(12.5 \mathrm{mg} / \mathrm{mL})$. Chlorhexidine (positive control) exhibited the potent antibacterial activity against $S$. mutans with the $\mathrm{MIC}$ and $\mathrm{MBC}$ of $<0.15 \mathrm{mg} / \mathrm{mL}$.

\section{Sucrose-dependent adherence assay and sucrose- independent adherence assay}

The ethanolic extracts of guava leaves, licorice roots and cloves at every concentration tested (at lower than their MICs) significantly inhibited both sucrose-dependent and sucrose-independent surface adherences of $S$. mutans $(p<0.05)$ (Figure 1). The three extracts exhibited their antiadherence actions in a concentration-dependent manner. The highest anti-adherence action was found when the highest concentration of the guava leaf ethanolic extract $(1 \mathrm{mg} / \mathrm{mL})$ was tested with the $\%$ adherence of only 1.50 and 8.43 in the sucrose-dependent and sucroseindependent adherence assays, respectively. These inhibitory actions against $S$. mutans surface adherence of the guava leaf ethanolic extract were significantly higher than those of the ethanolic extracts of licorice roots and cloves at the highest concentrations tested $(p<0.05)$.

\section{Biofilm formation assay}

The biofilm formations at $6,12,20$ and 24 hours were significantly decreased when $S$. mutans were incubated with the ethanolic extracts of guava leaves, licorice roots and cloves at every concentration tested (at lower than their MICs) $(p<0.05)$ (Figure 2). The extracts inhibited biofilm formation in a concentration-dependent manner. However, the inhibitory actions of the guava leaf extract at any concentration tested against biofilm formation at 24 -hour incubation were quite similar. The maximal \% inhibitions of biofilm formation of $99.34 \pm 0.11,98.53 \pm 0.08$ and $99.63 \pm 0.08$ were determined when the highest concentrations of the ethanolic extracts of guava leaves, licorice roots and cloves were used, respectively.

\section{Glycolytic pH drop assay}

The initial rates of glycolytic pH drop were significantly declined with the incubations of the ethanolic extracts of guava leaves, licorice roots and cloves at every concentrations tested (at lower than their MICs) $(p<0.05)$ (Table 3). The inhibitory actions against $S$. mutans acid production depended on the concentrations of the extract used. The clove ethanolic extract at the highest concentration used $(1 \mathrm{mg} / \mathrm{mL})$ showed the maximal inhibition against glycolytic $\mathrm{pH}$ drop with the initial rate of $\mathrm{pH}$ drop of $0.0378 \pm 0.0036 \mathrm{unit} / \mathrm{min}$.

\section{DISCUSSION}

The ethanolic extracts of guava leaves, licorice roots and cloves possessed the antibacterial activity against $S$. mutans with the MICs of $1.562,0.195$ and $1.562 \mathrm{mg} / \mathrm{mL}$, respectively. The ethanolic extract of licorice roots also exhibited the bactericidal activity against $S$. mutans with the MBC of $3.12 \mathrm{mg} / \mathrm{mL}$. Nonetheless, the bactericidal activity was not found with the ethanolic extracts of guava leaves and cloves at the maximal concentration tested $(12.50 \mathrm{mg} / \mathrm{mL})$. The ethanolic extracts of guava leaves, licorice roots and cloves at every concentration tested (lower than their MICs) also significantly inhibited the cariogenic properties of $S$. mutans, i.e. sucrose-dependent and sucrose-independent surface adherences, biofilm formation and acid production. The extracts performed their anti-cariogenic activities

Table 1: Phytochemical analysis of the ethanolic extracts of guava leaves, licorice roots and cloves by using TLCdensitometry $(n=5)$.

\begin{tabular}{ccccc}
\hline \multicolumn{2}{c}{ Phytochemical standard } & \multicolumn{2}{c}{ Extract } \\
\hline Agent & Rf value $(\lambda 254 \mathrm{~nm})$ & Extract & $\begin{array}{c}\text { Rf value } \\
(\lambda 254 \mathrm{~nm})\end{array}$ & $\begin{array}{c}\text { Phytochemical concentration in } \\
\text { the extract }(\%(w / w))\end{array}$ \\
\hline Quercetin & 0.65 & Guava leaves & 0.62 & 0.42 \\
Glycyrrhizic acid & 0.12 & Licorice roots & 0.10 & 0.81 \\
Eugenol & 0.75 & Cloves & 0.74 & 0.31 \\
\hline
\end{tabular}

Table 2: The antibacterial activity against $S$. mutans of the ethanolic extracts of guava leaves, licorice roots and cloves $(n=4)$.

\begin{tabular}{ccc}
\hline \multirow{2}{*}{ Test agent } & \multicolumn{2}{c}{ Concentration $(\mathrm{mg} / \mathrm{mL})$} \\
\cline { 2 - 3 } & MIC & MBC \\
\hline Guava leaf extract & 1.562 & $>12.500$ \\
Licorice root extract & 0.195 & 3.120 \\
Clove extract & 1.562 & $>12.500$ \\
Chlorhexidine 0.12\% & $<0.150$ & $<0.150$ \\
\hline
\end{tabular}




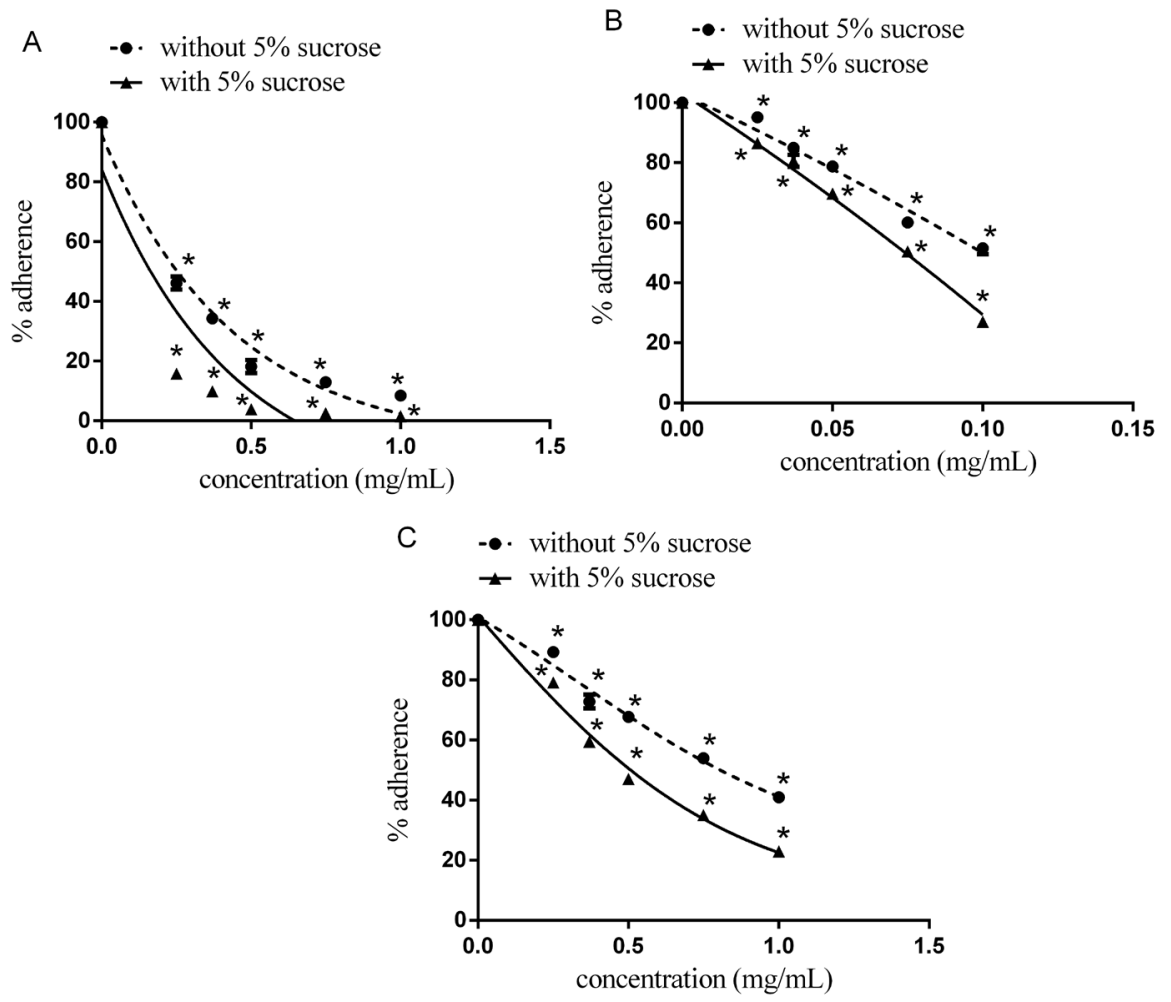

Figure 1: The effects of the ethanolic extracts of guava leaves (A), licorice roots (B) and cloves (C) on sucrose-dependent and sucrose-independent surface adherences of S. mutans. ${ }^{*} p<0.05$ when compare with a negative control $(n=4)$.
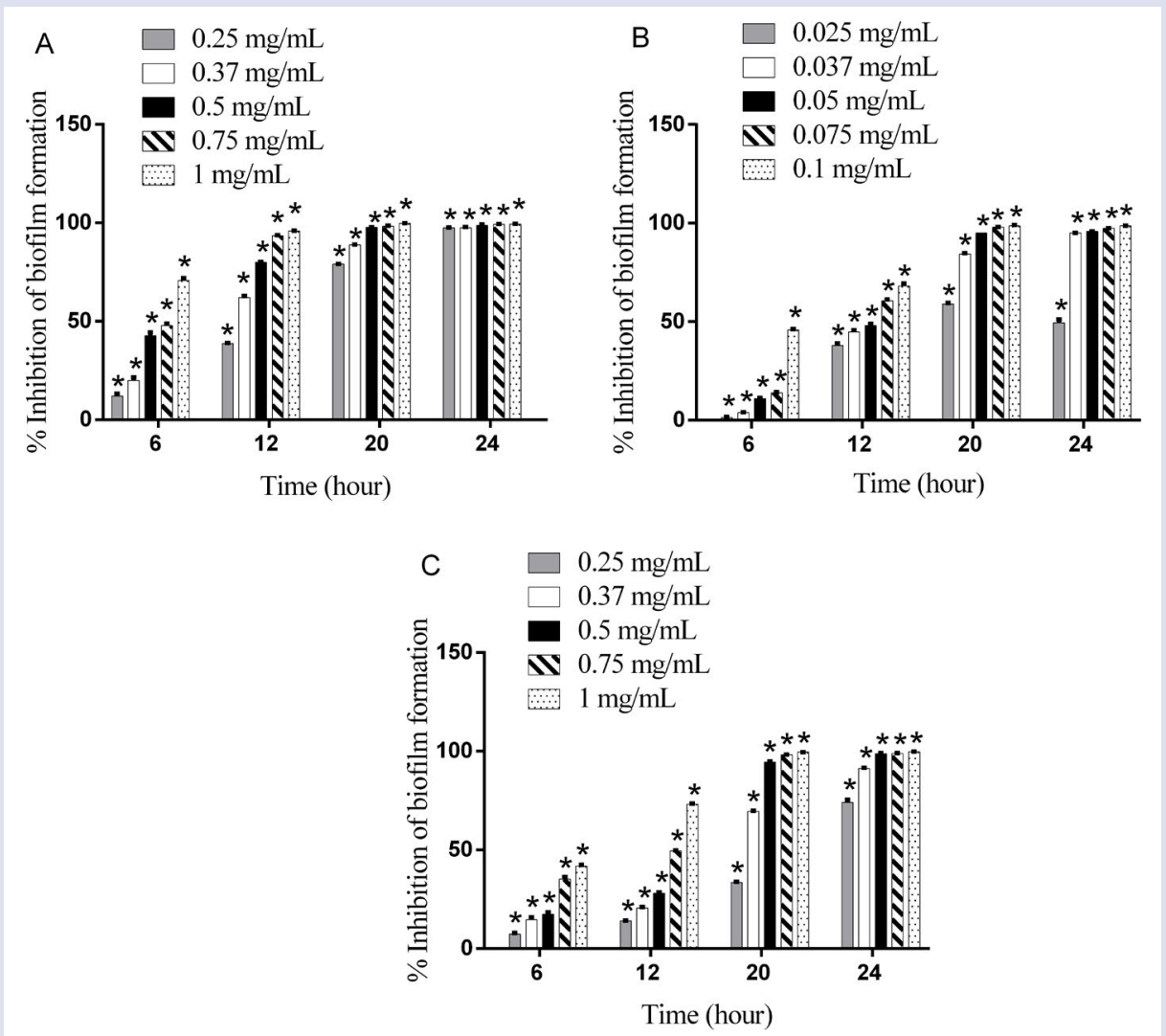

Figure 2: The effects of the ethanolic extracts of guava leaves (A), licorice roots (B) and cloves (C) on biofilm formation of $S$. mutans. ${ }^{*} p<0.05$ when compare with a negative control $(n=4)$. 
Table 3: The effects of the ethanolic extracts of guava leaves, licorice roots and cloves on initial rate of glycolytic pH drop.

\begin{tabular}{ccc}
\hline Extract & $\begin{array}{c}\text { Concentration } \\
(\mathrm{mg} / \mathrm{mL})\end{array}$ & $\begin{array}{c}\text { Initiate rate of pH drop (unit/min) } \\
\text { (mean } \pm \text { SD) }\end{array}$ \\
\hline Guava leaves & 0.000 & $0.2443 \pm 0.0010$ \\
& 0.250 & $0.1358 \pm 0.0063^{*}$ \\
& 0.370 & $0.1443 \pm 0.0028^{*}$ \\
Licorice root & 0.500 & $0.1445 \pm 0.0034^{*}$ \\
& 0.750 & $0.1245 \pm 0.0006^{*}$ \\
1.000 & $0.0453 \pm 0.0025^{*}$ \\
& 0.000 & $0.2545 \pm 0.0019$ \\
& 0.025 & $0.2235 \pm 0.0013^{*}$ \\
& 0.037 & $0.2165 \pm 0.0013^{*}$ \\
& 0.050 & $0.0940 \pm 0.0008^{*}$ \\
Cloves & 0.075 & $0.0755 \pm 0.0013^{*}$ \\
& 0.100 & $0.0718 \pm 0.0015^{*}$ \\
& 0.000 & $0.1975 \pm 0.0041$ \\
& 0.250 & $0.1280 \pm 0.0082^{*}$ \\
& 0.370 & $0.0990 \pm 0.0060^{*}$ \\
& 0.500 & $0.0540 \pm 0.0022^{*}$ \\
0.750 & $0.0543 \pm 0.0046^{*}$ \\
& 1.000 & $0.0378 \pm 0.0036^{*}$ \\
\hline
\end{tabular}

${ }^{*} p<0.05$ when compare with a negative control $(\mathrm{n}=4)$

in a concentration-dependent manner. Since the inhibitory actions against the cariogenic properties of $S$. mutans were observed even at the concentrations of lower than MICs, the extracts thus impeded the virulence of $S$. mutans without affecting their viability.

The antibacterial activity of the ethanolic extract of guava leaves against $S$. mutans presented here was similar to the previous study of Wannachot (2015). ${ }^{4}$ Berto (2014) also reported the approximate MIC of $1 \mathrm{mg} / \mathrm{mL}$ of the guava leaf ethanolic extract against $S$. mutans. ${ }^{14}$ However, the lower MIC of $250 \mu \mathrm{g} / \mathrm{mL}$ was found in the study of Braga et al. (2014). ${ }^{15}$ The TLC-densitometry analysis indicated that quercetin was an active compound found in the ethanolic extract of guava leaves with the amount of $0.42 \%$. This is in agreement with the study of Sohafy et al. (2009), in which the quercetin amount of $0.39 \%$ was found in the guava leaf extract. ${ }^{16}$ Quercetin is the flavonoids with antibacterial activity against various types of bacteria causing dental caries including S. mutans. ${ }^{17,18}$ It was proposed that quercetin exhibited its antibacterial activity by interfering with bacterial extracellular protein and cell membrane functions. The anti-cariogenic activity of quercetin has not been clearly established. Nonetheless, it was demonstrated that quercetin significantly inhibited biofilm formation, an important virulence factor, of Pseudomonas aeruginosa. ${ }^{19}$ In addition to quercetin, guaijaverin, which is another flavonoid presented in the guava leaf extract, also possessed the antibacterial activity against $S$. mutans. Guaijaverin notably inhibited $S$. mutans surface adherence by reducing the bacterial surface hydrophobicity. Guaijaverin has also been found to inhibit acid production and sucrose-dependent and sucroseindependent surface adherences of $S$. mutans. ${ }^{11}$ Thus, guaijaverin may also play a dominant role in the anti-cariogenic activities of the guava leaf ethanolic extract.

The antibacterial activity of the licorice root ethanolic extract against $S$. mutans was reported with the MIC and MBC of 12.5 and 25 $\mathrm{mg} / \mathrm{mL}$, respectively in the study of Sedighinia et al. (2012). ${ }^{20}$ Whereas Chaiya et al. (2013) described the lower MIC value of less than $12.5 \mathrm{mg} /$ $\mathrm{mL}$ and the $\mathrm{MBC}$ of $25 \mathrm{mg} / \mathrm{mL}^{3}$ These are somewhat dissimilar to the current results in which the MIC and MBC values of 0.195 and $3.12 \mathrm{mg} /$ $\mathrm{mL}$, respectively were determined in the licorice root ethanolic extract. The differences in plant source and method of extraction which give rise to a variation in active phytochemical contents may be a reason for the discrepancy. Nonetheless, the MBC value of the ethanolic licorice root extract reported here is quite similar to the result of Geetha and Anitha (2012) in which the MBC of $2 \mathrm{mg} / \mathrm{mL}$ was documented. ${ }^{21}$ The ethanolic extract of licorice roots at every concentration tested (at lower than their MIC) significantly inhibited surface adherence, biofilm formation and acid production of $S$. mutans. The phytochemical analysis indicated that an active compound in the licorice root ethanolic extract was glycyrrhizic acid (GA) with the amount of $0.81 \%$. This is in agreement with the report of Tian, Yan, and Row (2008) in which the GA amount of $0.86 \%$ was found in the licorice root ethanolic extract. ${ }^{22}$ It was found that GA (0.5-1\%) effectively abolished cell surface adherence and biofilm formation of $S$. mutans. ${ }^{23}$ Thus, GA is possibly involved in the anti-cariogenic effects of the licorice root extract found in this study. However, it was reported that the deglycyrhizinated licorice extract (the licorice extract without GA) still possessed the antibacterial activity against $S$. mutans. ${ }^{24}$ The deglycyrhizinated licorice extract also significantly inhibited the biofilm formation of the clinical isolates of $S$. mutans. ${ }^{25}$ Additionally, glabridin extracted from licorice root was found to have the antibacterial activity against $S$. mutans with the MIC of 7.5 $\mathrm{mg} / \mathrm{mL} .{ }^{26}$ Thus, other active phytochemicals, apart from GA, may also be linked with the anti-cariogenic activities of the licorice root extract.

The anti-S. mutans activity of the clove ethanolic extract was found with the MIC of $1.526 \mathrm{mg} / \mathrm{mL}$, whilst the MBC could not be determined when the highest concentration tested of $12.5 \mathrm{mg} / \mathrm{mL}$ was used in this study. This is in agreement with the study of Wannachot (2015). However, the higher MIC values of $<12.5 \mathrm{mg} / \mathrm{mL}$ and $12.5 \mathrm{mg} / \mathrm{mL}$ were reported from the studies of Chaiya et al. (2013) and Mirpour, Siahmazgi, and Kiasaraie (2015), respectively., ${ }^{3,27}$ The relatively high MBCs of 50 and $25 \mathrm{mg} / \mathrm{mL}$ were also described in those two studies. The clove ethanolic extract at every concentration tested (at lower than their MIC) substantially inhibited surface adherence, biofilm formation and acid production of $S$. mutans. This is in agreement with the report of Rahim and Khan (2006) who demonstrated the inhibitory activities of the aqueous and methanolic extracts of clove $(5-15 \mathrm{mg} / \mathrm{mL})$ against cariogenic properties of $S$. mutans. ${ }^{28}$ The anti-cariogenic activities of clove oil were also presented by Moon, Kim and Cha (2011). ${ }^{29}$ The active compound found in the clove extract was eugenol with the amount of approximately $60-95 \% .{ }^{30}$ Nonetheless, the eugenol amount of $0.31 \%$ was detected in the clove ethanolic extract in this study. This difference 
may be due to distinctions in plant source and method of extract preparation. Although the amount of eugenol found was relatively low when compare to those reported earlier by other investigators, the clove ethanolic extract still exhibited considerable bioactivities in this study. Other phytochemical presented in the clove ethanolic extract, such as caryophyllene is thus likely to play a role against $S$. mutans. ${ }^{31,32}$ This active phytochemical may act together with eugenol to produce a synergistic action against $S$. mutans. ${ }^{33}$ The antibacterial activity of eugenol against $S$. mutans was evidenced with the MIC and MBC of 100 and $200 \mu \mathrm{g} / \mathrm{mL}$, respectively. ${ }^{29}$ Clove oil (0.001-0.1\%) and eugenol (0.002 and $0.005 \%)$ inhibited Escherichia coli biofilm formation by suppressing the expressions of biofilm-forming related genes and interfering with cell surface adherence. ${ }^{34}$ It is therefore possible that eugenol may also act as an active phytochemical with antibacterial and anticariogenic activities against $S$. mutans in the ethanolic clove extract in the present study.

The quantitative evaluation of phytochemical marker could be used in herbal standardization to indicate its quality especially when that chemical constituent attributed its biological or pharmacological activity. Although there are many other components presented in the extracts, we selected only these three compounds, quercetin, glycyrrhizic acid, eugenol, since they are the major bioactive phytochemicals which can be used for herbal extract standardization.

\section{CONCLUSION}

In summary, the ethanolic extracts of guava leaves, licorice roots and cloves significantly inhibited the growth of $S$. mutans and the extracts at the concentrations of lower than their MICs also suppressed the cariogenic properties of $S$. mutans by inhibitions of sucrose-dependent and sucrose-independent surface adherences, biofilm formation and acid production. These results strongly suggest the potential use of the three extracts as active ingredients in oral health-care product for the prevention of dental caries. Since the extracts inhibited the virulence factors of $S$. mutans even at lower than their MICs, only small amount of the extracts would be essentially incorporated during a preparation of an oral health-care product. This possibly lessens an incompatibility, which is a major common problem found during herbal product formulations. Additionally, a formulation-related problem of undesired color, taste and odor caused by the extracts would also be abated when only modest amount of the extracts is required in the preparation. Nonetheless, further in vivo experiments are still required to confirm this finding.

\section{ACKNOWLEDGMENTS}

This project is partially supported by a postgraduate research grant, Mahasarakham University year 2017.

\section{REFERENCES}

1. Bureau of dental health, National dental health survey report. Department of health: Ministry of public health. Bangkok, Thailand;2007.

2. Trairatvorakul C. Early childhood caries. Faculty of dentistry, Chulalongkorn University. Bangkok, Thailand;2011.

3. Chaiya A, Saraya S, Chuakul W, Temsiririrkkul R. Screening for dental caries: Preventive activities of medicinal plants against Streptococcus mutans. PSA. 2013;40:9-17.

4. Wannachot J. Development and evaluation of herbal mouthwash formula against Streptococcus mutans. Faculty of Pharmacy, Mahasarakham University, Maha sarakham, Thailand. 2015.

5. Razak FA, Rahim ZHA. The anti-adherence effect of Piper betle and Psidium guajava extracts on the adhesion of early settlers in dental plaque to salivacoated glass surfaces. J Oral Sci. 2003;45:201-6.

6. Anderson DM, Smith WG. The antitussive activity of glycyrrhetinic acid and its derivatives. JPP. 1961;13:396-404.

7. Aneja KR, Joshi R. Antimicrobial activity of Syzygium aromaticum and its bud oil against dental caries causing microorganisms. Ethnobot Leaflets. 2010;14:960-75.
8. Rattana S, Sungthong B, Lertsatithanakorn P. Simultaneous separation of glycyrrhizic acid and gallic acid in cinnamon stomachic mixture extract by thin layer chromatography-densitometric method and screening of anti-free radical substances by bioautographic method. IJPS. 2017;13:60-71.

9. Moody J. Synergism testing: Broth microdilution checkerboard and broth macrodilution methods. In: Isenber HD, Editor. Clinical microbiology procedures handbook, 2nd ed. Washington DC: American Society for Microbiology Press. 2004.

10. Ajagannanavar SL, Battur $H$, Shamarao S, Sivakumar V, Patil PU, Shanavas P. Effect of aqueous and alcoholic licorice (Glycyrrhiza Glabra) root extract against Streptococcus mutans and Lactobacillus acidophilus in comparison to chlorhexidine: An in vitro study. J Int Oral Health. 2014;6:29-34.

11. Prabu GR, Gnanamani A, Sadulla S. Guaijaverin - A plant flavonoid as potentia antiplaque agent against Streptococcus mutans. JAM. 2006;101:487-95.

12. Bowen WH, Koo H. Biology of Streptococcus mutans-deriverd glucosyltransferases: Role in extracellular matrix formation of cariogenic biofilms. Caries Res. 2011;45:69-86.

13. Yang $Y$, Liu S, He Y, Chen Z, Li M. Effect of LongZhang gargle on biofilm formation and acidogenicity of Streptococcus mutans in vitro. BMRI. 2016;1:1-8.

14. Berto LA. Antimicrobial activity of plants from brazilian cerrado against Streptococcus mutans. Piracicaba Dental School of the University of Campinas, Brazil. 2014.

15. Braga TV, Dores RGR, Ramos CS, Evangelista FCG, Tinoco MS, Varotti FP, et al. Antioxidant, antibacterial and antitumor activity of ethanolic extract of the Psidium guajava leaves. AJPS. 2014;5:3492-500.

16. Sohafy SM, Metwalli AM, Harraz FM, Omar AA. Quantification of flavonoids of Psidium guajava L. preparations by planar chromatography (HPTLC). Phcog Mag. 2009;5:61-6.

17. Geoghegan F, Wong RW, Rabie AB. Inhibitory effect of quercetin on periodontal pathogens in vitro. Phytother Res. 2010;24:817-20.

18. Shu Y, Liu Y, Li L, Feng J, Lou BY, Zhou XD, et al. Antibacterial activity of quercetin on oral infectious pathogens. Afr J Microbiol Res. 2011;5:5358-61.

19. Ouyang J, Sun F, Feng W, Sun Y, Qiu X, Xiong L, et al. Quercetin is an effective inhibitor of quorum sensing, biofilm formation and virulence factors in Pseudomonas aeruginosa. JAM. 2016;120:966-74.

20. Sedighinia F, Afshar AS, Soleimanpour S, Zarif R, Asili J, Ghazvini K. Antibacterial activity of Glycyrrhiza glabra against oral pathogens: An in vitro study. AJP. 2012;2:118-24.

21. Geetha RV, Anitha R. In vitro evaluation of antibacterial activity of ethanolic root extract of Glycyrrhiza glabra on oral microbes. IJDDR. 2012;4:161-5.

22. Tian $M$, Yan $H$, Row $\mathrm{KH}$. Extraction of glycyrrhizic acid and glabridin from licorice. IJMS. 2008;9:571-7.

23. Segal R, Pisanty S, Wormser R, Azaz E, Sela MN. Anticariogenic activity of licorice and glycyrrhizine 1: Inhibition of in vitro plaque formation by Streptococcus mutans. J Pharm Sci. 1985;74:79-81.

24. Ahn SJ, Cho EJ, Kim HJ, Park SN, Lim YK, Kook JK. The antimicrobial effects of deglycyrrhizinated licorice root extract on Streptococcus mutans UA159 in both planktonic and biofilm cultures. Anaerobe. 2012;18:590-660.

25. Ahn SJ, Song YD Mah SJ, Cho EJ, Kook JK. Determination of optimal concentration of deglycyrrhizinated licorice root extract for preventing dental caries using a bacterial model system. JDS. 2014;9:214-20.

26. Gupta VK, Fatima A, Faridi U. Antimicrobial potential of Glycyrrhiza glabra roots. J Ethnopharmacol. 2008;116:377-80.

27. Mirpour M, Siahmazgi ZG, Kiasaraie MS. Antibacterial activity of clove, gall nut methanolic and ethanolic extracts on Streptococcus mutans PTCC 1683 and Streptococcus salivarius PTCC 1448. JOBCR. 2015;5:7-10.

28. Rahim ZHA, Khan HBSG. Comparative studies on the effect of crude aqueous (CA) and solvent (CM) extracts of clove on the cariogenic properties of Streptococcus mutans. J Oral Sci. 2006;48:117-23.

29. Moon SE, Kim HY, Cha JD. Synergistic effect between clove oil and its major compounds and antibiotics against oral bacteria. Arch Oral Biol. 2011;56:90716.

30. Sunthorncharoennon N, Reangwisad N. A quality of Thai traditional medicines: From research to sustainable development. National Research Council of Thailand. Bangkok, Thailand. 2008.

31. Sarasa D. Phytochemical and GC-MS analysis of ethanol extract of Syzygium aromaticum. WJPPS. 2017;6(8):1143-51.

32. Yoo HJ, Jwa SK. Inhibitory effects of $\beta$-caryophyllene on Streptococcus mutans biofilm. Arch Oral Biol. 2018;88:42-6.

33. Marchese A, Barbieri R, Coppo E, Orhan IE, Daglia M, Nabavi SF, et al. Antimicrobial activity of eugenol and essential oils containing eugenol: A mechanistic viewpoint. Crit Rev Microbiol. 2017;43(6):668-89.

34. Kim YG, Lee JH, Kim SI, Park JG, Lee JT. Essential oils and eugenols inhibit biofilm formation and the virulence of Escherichia coli O157:H7. Sci Rep. 2016;6:1-11. 


\section{GRAPHICAL ABSTRACT}

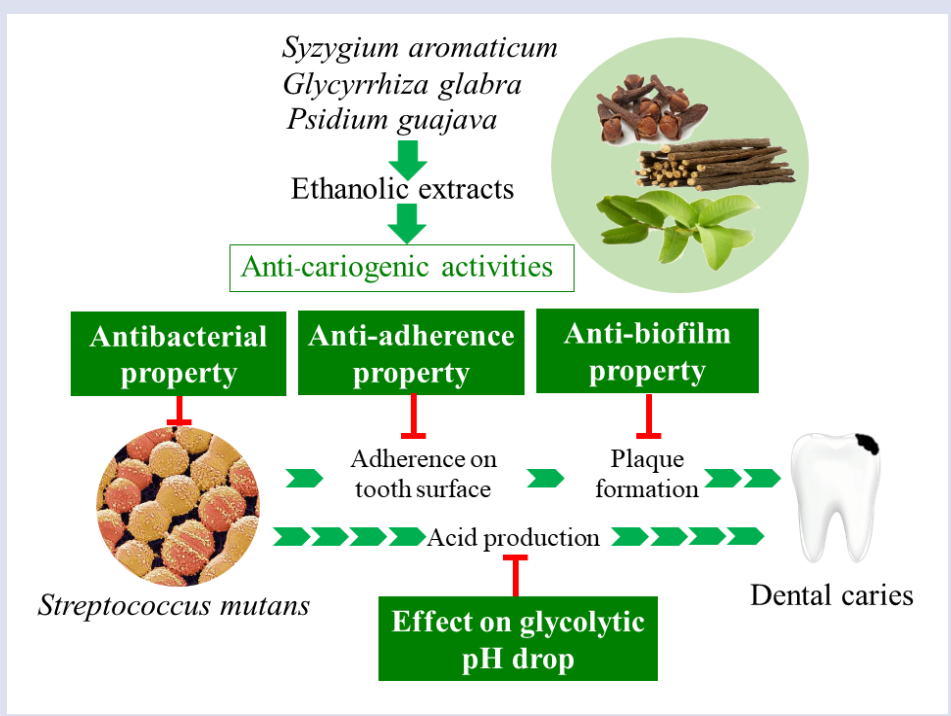

\section{ABOUT AUTHORS}

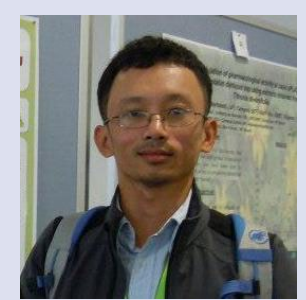

Name: Bunleu Sungthong

Contact: Faculty of Pharmacy, Mahasarakham University, Mahasarakham, Thailand 44150

E-mail: bunleu.s@msu.ac.th

Mobile Phone: (66) 84-597-2464

Education:

Doktor der Naturwissenschaften (Pharmazie), Friedrich-Schiller-University, Jena, Germany, 2010

Master of Pharmacy (Pharmaceuticals), Faculty of Pharmaceutical Sciences, Khon Kaen University, 2003

Bachelor of Pharmacy, Faculty of Pharmaceutical Sciences, Khon Kaen University, 1998

Currently, Dr. Sungthong has been appointed an Assistant Professor in Pharmaceutical Sciences at the Faculty of Pharmacy, Mahasarakham University, Thailand. He is working on medicinal plant researches focusing on analysis of plant secondary metabolites and their biological activity assays.

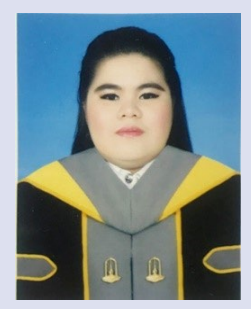

Name: Nalita Phaiboon

Contact: Faculty of Pharmacy, Mahasarakham University, Mahasarakham, Thailand 44150

E-mail: nalitayj@gmail.com

Mobile Phone: (66)-82-150-5758

Current Position: Graduate student (Master of Sciences Program in Medicinal Plants and Natural Products)

Education:

M.Sc. in Medicinal Plants and Natural Products, Faculty of Pharmacy, Mahasarakham University, 2019

B. Sc. In Chemitry, Faculty of Science, Mahasarakham University, 2015.

Name: Pawitra Pulbutr, Ph.D.

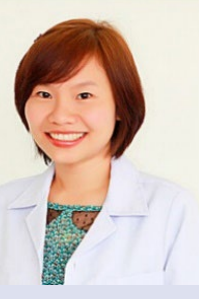

Contact: Faculty of Pharmacy, Mahasarakham University, Maha Sarakham, Thailand 44150

E-mail: pawitra.p@msu.ac.th

Mobile Phone: (66)-87-589-1543

Current Position: Assistant Professor, Faculty of Pharmacy, Mahasarakham University, Thailand

Area of interest: Pharmacology of the endocrine system, Biological activity of medicinal plants and natural products

Education:

Ph.D. (Physiology and Pharmacology), School of Biomedical Sciences, The University of Nottingham, Nottingham, UK, 2009

M.Sc. in Pharmacy (Pharmacology), Faculty of Pharmacy, Mahidol University, 2001

B. Pharm ( $1^{\text {st }}$ Honorary), Faculty of Pharmacy, Chiang Mai University, 1999. 
Name: Sakulrat Rattanakiat, Ph.D.

Contact: Faculty of Pharmacy, Mahasarakham University, Maha Sarakham, Thailand 44150

E-mail: sakulrat.r@msu.ac.th

Mobile Phone: (66)-86-771-8949

Current Position: Assistant Professor, Faculty of Pharmacy, Mahasarakham University, Thailand

Area of interest: Microbiology, Biological activity of medicinal plants and natural products

Education:

2009: PhD (Pharmaceutical Sciences) Graduate School of Pharmaceutical Sciences, Kyoto University, Japan

2002: MSc in Pharm (Microbiology) Faculty of Pharmaceutical Sciences, Chulalongkorn University

2000: BSc in Pharm (1 ${ }^{\text {st }}$ Honorary) Faculty of Pharmaceutical Sciences, Chulalongkorn University.

Cite this article: Phaiboon N, Pulbutr P, Sungthong B, Rattanakiat S Effects of the Ethanolic Extracts of Guava Leaves, Licorice Roots and Cloves on the Cariogenic Properties of Streptococcus mutans. Pharmacog J. 2019;11(5):1029-36. 